cholinergic receptors. It proved possible to release the labelled toxin-receptor complex from the membrane fragments by treatment with a low concentration of the detergent 'Triton X-100', and the toxin-receptor complex was then purified by chromatography and density gradient centrifugation. On chromatography in the presence of detergents the toxin-receptor complex could be clearly separated from the enzyme acetylcholinesterase. The purest fractions obtained contained $1 \mu \mathrm{g}$ of bungarotoxin per $10 \mathrm{~m} \mu \mathrm{g}$ membrane protein, suggesting a molecular weight for the receptor protein of approximately 80,000 . In the absence of detergent, the receptor protein formed aggregates of 500,000-2,000,000 molecular weight. In low concentrations of 'Triton' the receptor protein seemed to consist of a tetrameric form of the 80,000 molecular weight subunits. As in the experiments of Changeux et al., the number of bungarotoxin binding sites in Torpedo tissue was approximately equal to the number of acetylcholinesterase catalytic sites. If the receptor protein normally exists as a tetramer, as is the case with acetylcholinesterase, this would imply that the electric tissue membrane contains equal numbers of enzymes and receptor molecules. Miledi et al. estimated the number of bungarotoxin binding sites as approximately $10,000 / \mu^{2}$ of cell membranes.

Although the present reports from the Paris-Taiwan and London groups are clearly preliminary, it would seem that the use of bungarotoxin is well grounded on pharmacological evidence. These findings thus offer a great potential for future studies on the molecular mechanisms involved in drug-receptor interaction. Pharmacologists and molecular biologists may be justified in wondering whether this does not constitute at least a partial redemption for the serpent.

\title{
Aftermath of the Revolution
}

THE importance of the article by Baker and Wohlenberg on page 538 of this issue of Nature lies as much in the philosophy behind it as in the geological and geophysical knowledge it embodies. For it acknowledges that geology is coming to terms at last with the global model of the Earth which geophysics has imposed on it; and it marks the end of the fear that the vast intellectual edifice constructed by geologists since the ages of Hutton and Lyell must be completely demolished in the light of the new global tectonics. The reality is, of course, far less severe than the fear. For a century or more geologists were much concerned with detailed examination of small regions of the Earth's surface, from which they would attempt to generalize to the larger world. The problem was that, through no fault of their own, they were never able to generalize successfully to the extent of constructing a valid world model. That geophysicists have in less than ten years been able to do just that proves not so much that the geologists were wrong but only that the tools at their disposal were not up to the task.

The way ahead is thus not to destroy the old geology but to reinterpret its legacy in terms of the new global tectonics. And to their credit, Baker and Wohlenberg have recognized this. The purpose of their article is, they say, "to summarize modern geological knowledge of the Kenya rift and to reconcile this with crustal models and kinematic concepts derived primarily from geophysical data". They are surely right in seeing this as the logical procedure to follow in the wake of what J. Tuzo Wilson has so aptly termed the revolution in the Earth sciences.

The scientific point to emerge from the reconciliation is not perhaps the surprise it would have been a few years ago. Baker and Wohlenberg conclude that although the East African rift is linked to, and at first sight seems to be a continuation of, the world oceanic ridge system, it is neither typical of that system nor probably an example of the first stage of continental breakup. In rejecting the idea that rift valleys are the simple land based equivalents of the median valleys of oceanic ridges, and in attributing the former instead to "long-continued interaction between crust and thermally activated mantle", Baker and Wohlenberg have thus followed a different route to arrive at a conclusion similar to Murray's (Earth Planet. Sci. Lett., 9, 34; 1970), which was based on geochemical evidence. At the same time they confirm the suspicions generated by the discovery that the heat flow over the East African rift is, if anything, lower than the world average and not abnormally high as over oceanic ridges.

There is, of course, some irony in that although Baker and Wohlenberg have enthusiastically embraced the new global tectonics, they have been instrumental in destroying one of its most cherished myths. But there is no harm in that. If geophysicists have a fault it is that they have sometimes tended to exaggerate the extent to which the simple tenets of global tectonics apply to the real world. So there is nothing to be lost by a few counterbalancing jolts from time to time. It is a pity, though, that when Baker and Wohlenberg wrote their article they did not have at their disposal the seismic refraction and gravity data from the Gregory rift described a few weeks ago by Griffiths et al. and Khan and Mansfield in Nature Physical Science $(229,69$ and $72 ; 1971)$. The crustal model proposed by Khan and Mansfield, in particular, is somewhat different from those proposed earlier; and to this extent Baker and Wohlenberg may have wished to revise some of their details in the light of the new evidence.

Surprisingly, perhaps, the seismic refraction study of the Gregory rift carried out recently by Griffiths et al. was the first attempt to determine the detailed crustal structure in this region. In spite of the widespread interest in the East African rift, first as an extension of the worldwide system and now because it is thought to be in some respects different from the rest of the system, the amount of work done there is remarkably small. Which is a pity. For one reason or another the large American geophysical community has never taken much interest in this important region; and what studies there are have been carried out chiefly by British and Kenyan scientists working either separately or in collaboration.

In view of the importance of finding out just what are the differences and similarities between the East African rift and the oceanic ridges, the time has surely come to mount a geophysical and geological attack on this region. 